\title{
Prevalence of Raynaud's phenomenon in Great Britain and its relation to hand transmitted vibration: a national postal survey
}

\author{
Keith T Palmer, Michael J Griffin, Holly Syddall, Brian Pannett, Cyrus Cooper,
} David Coggon

\begin{abstract}
Objectives-To assess the prevalence of Raynaud's phenomenon in the general population of Great Britain and to estimate the proportion and number of cases attributable to hand transmitted vibration (HTV).

Methods-A questionnaire was posted to a random sample of 22194 adults of working age. Information was collected on the lifetime prevalence of finger blanching, smoking habits, and occupational and leisure time exposures to HTV. Associations with risk factors were explored by logistic regression, with odds ratios converted into prevalence ratios (PRs).

Results-Among the 12907 respondents, $1835(14.2 \%)$ reported finger blanching at some time, including $1529(11.8 \%)$ in whom symptoms were induced by cold, and $597(4.6 \%)$ in whom the blanched area was also clearly demarcated. Prevalences were higher in women than men. Around one fifth of cases ( $2 \%$ of respondents) had consulted a doctor about their symptoms. By comparison with men who had never been exposed to HTV, the PR for cold induced blanching in those exposed only at work was 2.0 (95\% CI 1.7 to 2.3$)$, and in men exposed both at work and in leisure it was 2.5 (95\% CI 2.1 to 3.1$)$. Higher risks were found in men who consulted a doctor about cold induced blanching, among whom $37.6 \%$ of cases were estimated to arise from exposure to HTV. The estimated number of cases attributable to HTV nationally was 222000 in men who reported extensive blanching (blanching affecting at least eight of the digits or 15 phalanges). Similar patterns of risk were found in women, but the attributable proportion was much lower $(5.3 \%$ in cases consulting a doctor).

Conclusions-Raynaud's phenomenon is common in the general population. Many cases are attributable to HTV, especially in men, emphasising the public health importance of this common occupational hazard.

(Occup Environ Med 2000;57:448-452)
\end{abstract}

Keywords: Reynaud's phenomenon; vibration induced white finger; population; attributable number; vibration

Correspondence to:

Dr Keith Palmer

ktp@mrc.soton.ac.uk

Accepted 25 February 2000

Raynaud's phenomenon is a common disorder, characterised by episodic blanching of the fin- gers, typically in response to cold. ${ }^{12}$ The symptoms vary in severity from minor to disabling. Often no underlying cause for the condition can be identified, but sometimes it results from exposure to hand transmitted vibration (HTV) through the use of vibratory tools and machines. Such exposure usually occurs occupationally, and vibration induced white finger is a well established consequence of the hazard in industries such as forestry, mining, and quarrying. ${ }^{3-9}$

Exposure to HTV is common in Britain. ${ }^{10}$ However, its contribution to the overall prevalence of Raynaud's phenomenon in the community is unknown. Better information about this would help in the prioritisation of preventive measures, and might facilitate compensation for patients who have been injured through their work.

To find out more about the prevalence of Raynaud's phenomenon in the general population and its association with exposure to HTV, we carried out a postal survey.

\section{Methods}

The study sample comprised 22415 men and women aged 16-64 years. Of these, 21422 were randomly selected from the registration lists of 34 general practices in geographically dispersed locations across England, Wales, and Scotland, and 993 were chosen at random from members of the armed forces resident in Britain. After exclusion of individual people whom the general practitioners advised us not to contact - for example, because of recent illness or bereavement-all remaining subjects were sent a postal questionnaire with a covering letter signed by their general practitioner, or in the armed forces by the Director of General Medical Services. Two batches were posted, the first in May and June 1997 and the second in January 1998. Non-responders were sent a single reminder after 5 weeks. Further details of the procedures have been published. ${ }^{10}$

The development of the questionnaire has also been described in an earlier report. ${ }^{11}$ Among other things it asked about current occupation; whether the subject had used 39 specified tools or machines (recognised sources of HTV) at work in the previous week; whether he or she had ever had a paid job which involved working with a powered tool or machine that made the hands vibrate for more than 1 hour a week; whether he or she had been exposed regularly for at least 1 hour a week to 
she had driven industrial vehicles such as tractors and fork lift trucks that are a source of whole body vibration; smoking habits; recent symptoms of headache and feeling tired or stressed; experience of low back pain in the past 12 months; and lifetime history of finger blanching (including any disability caused and resultant use of medical services).

Subjects were classified on the basis of their responses to three questions about finger blanching:

- Have you ever had attacks in which any or all of your fingers suddenly became cold and numb, and at the same time turned white or pale?

- If so, have the attacks ever been brought on by cold conditions?

- During an attack, have you ever noticed a clear edge between the white or pale part of your finger and the normal colour of your hand?

Associations between finger blanching and risk factors were examined by logistic regression, and the findings were expressed as prevalence ratios (PRs) with associated $95 \%$

Table 1 Lifetime prevalence of finger blanching by age and sex

\begin{tabular}{|c|c|c|c|c|}
\hline \multirow[b]{2}{*}{$\operatorname{Age}(y)$} & \multirow[b]{2}{*}{ Sample $(n) t$} & \multicolumn{3}{|c|}{ Lifetime prevalence $(\%)^{\star}$} \\
\hline & & $\begin{array}{l}\text { Any } \\
\text { blanching }\end{array}$ & $\begin{array}{l}\text { Cold induced } \\
\text { blanching }\end{array}$ & $\begin{array}{l}\text { Cold induced } \\
\text { blanching with } \\
\text { a clear edge }\end{array}$ \\
\hline \multicolumn{5}{|l|}{ Men: } \\
\hline $16-24$ & 814 & 7.5 & 6.3 & 1.8 \\
\hline $25-34$ & 1516 & 8.8 & 7.2 & 2.1 \\
\hline $35-44$ & 1609 & 12.5 & 9.7 & 3.9 \\
\hline $45-54$ & 1652 & 15.2 & 12.4 & 5.3 \\
\hline $55-65 \ddagger$ & 1317 & 20.6 & 17.5 & 7.2 \\
\hline \multicolumn{5}{|l|}{ Women: } \\
\hline $16-24$ & 787 & 9.2 & 8.3 & 3.5 \\
\hline $25-34$ & 1395 & 11.8 & 10.0 & 4.8 \\
\hline $35-44$ & 1424 & 17.0 & 14.6 & 6.3 \\
\hline $45-54$ & 1299 & 20.5 & 18.1 & 6.4 \\
\hline $55-65 \ddagger$ & 1089 & 19.4 & 15.9 & 5.1 \\
\hline
\end{tabular}

${ }^{\star}$ A few subjects failed to answer all of the questions on blanching. For each health outcome the prevalence was based on those subjects who answered the relevant questions.

†Excludes five subjects who did not provide their date of birth.

$\ddagger$ The sample included 72 subjects who were 64 when the mailing lists were assembled but 65 at the time the questionnaire was completed.

Table 2 Age and sex standardised prevalence of finger blanching according to timing of response and region of residence

\begin{tabular}{|c|c|c|c|c|}
\hline & \multirow[b]{2}{*}{$\begin{array}{l}\text { Sample } \\
(n) t\end{array}$} & \multicolumn{3}{|c|}{ Lifetime prevalence $(\%)^{*}$} \\
\hline & & $\begin{array}{l}\text { Any } \\
\text { blanching }\end{array}$ & $\begin{array}{l}\text { Cold induced } \\
\text { blanching }\end{array}$ & $\begin{array}{l}\text { Cold induced } \\
\text { blanching with } \\
\text { a clear edge }\end{array}$ \\
\hline \multicolumn{5}{|l|}{ Responded: } \\
\hline To winter mailing & 5261 & 14.5 & 12.3 & 4.6 \\
\hline To summer mailing & 6771 & 14.3 & 11.9 & 4.8 \\
\hline To armed forces mailing & 643 & 7.4 & 6.7 & 2.5 \\
\hline At first invitation & 9357 & 14.3 & 12.1 & 4.8 \\
\hline After a reminder & 3318 & 15.0 & 12.4 & 4.7 \\
\hline \multicolumn{5}{|l|}{ NHS region: } \\
\hline \multicolumn{5}{|l|}{ England } \\
\hline North West & 1061 & 15.0 & 13.3 & 4.7 \\
\hline Northern and Yorkshire & 3385 & 14.2 & 12.3 & 5.6 \\
\hline Trent & 1675 & 13.8 & 11.3 & 4.2 \\
\hline West Midlands & 1877 & 14.4 & 11.8 & 4.3 \\
\hline Eastern & 517 & 13.0 & 11.2 & 3.4 \\
\hline South West & 925 & 15.2 & 12.5 & 4.8 \\
\hline South East & 553 & 13.4 & 10.6 & 3.5 \\
\hline London & 495 & 14.7 & 10.0 & 4.2 \\
\hline Scotland & 879 & 15.6 & 13.0 & 4.1 \\
\hline Wales & 665 & 16.0 & 13.5 & 6.4 \\
\hline
\end{tabular}

^For each health outcome the prevalence was based on those subjects who answered the relevant questions, and standardised to the age and sex distribution of all respondents.

†Maximum number of subjects. Some subjects failed to answer all of the questions on blanching. confidence intervals (95\% CIs). These were derived from the corresponding odds ratios according to a formula proposed by Zochetti et $a{ }^{12}$ Attributable proportions (the proportions of cases of finger blanching that would be avoided if the excess prevalence associated with HTV were eliminated) were calculated from the relevant PRs and from an estimate of the prevalence of exposure to HTV nationally. This was derived from the prevalence in the study sample, standardised according to the distribution of occupations at the 1991 national census. ${ }^{13}$ Confidence intervals for attributable proportions were calculated by a bootstrap method. ${ }^{14}$

\section{Results}

Questionnaires were completed by 12907 $(58 \%)$ of the sample originally selected for study. Among the non-responders were 221 ( $1 \%$ of those selected) whom general practitioners advised us not to contact, 1028 (4.6\%) who had moved to an unknown address or died, and $56(0.25 \%)$ whose questionnaire was completed by someone other than the intended recipient. Non-response tended to be more common in the younger age bands and in men. The 12907 responders comprised 6913 men and 5994 women, and their occupational distribution was similar to that in the 1991 national census except that the armed forces were overrepresented. Further details of the pattern of response are reported elsewhere. ${ }^{10}$

Altogether, $1835(14.2 \%)$ of those who responded gave a history of finger blanching at some time, including $1529(11.8 \%)$ in whom the blanching was cold induced, and 597 $(4.6 \%)$ in whom there was also a clear edge to the blanched part of the finger. Table 1 shows the lifetime prevalence of blanching by age and sex. Complaints tended to be more common in women than men.

The prevalence of blanching (standardised to the age and sex distribution of all responders) was similar when questioned in the summer and winter, and was little different in subjects who responded to our first letter compared with those who only replied after a reminder. Nor were there any large regional differences in the age standardised prevalence of symptoms (table 2). There was, however, a lower age standardised frequency of complaints among members of the armed forces.

Table 3 shows the distribution of subjects with cold induced finger blanching according to the severity of symptoms and whether they had led to medical consultation. Most subjects reported that they had fewer than 10 episodes a year, but more than a third had at some time been obliged to discontinue an activity because of an attack, and one fifth $(2.0 \%$ of all men and $2.8 \%$ of all women who responded to the questionnaire) had consulted a doctor about the problem.

Cold induced finger blanching was reported more often by men and women who also said that they had had frequent headaches (PR 1.3, $95 \%$ CI 1.1 to 1.5$)$ or often felt tired or stressed (PR 1.6, 95\% CI 1.5 to 1.8 ). Table 4 shows the association of cold induced finger blanching 
Table 3 Severity of cold induced finger blanching

\begin{tabular}{|c|c|c|c|c|}
\hline & \multicolumn{2}{|c|}{ Men } & \multicolumn{2}{|c|}{ Women } \\
\hline & $n$ & $\% *$ & $n$ & $\%$ * \\
\hline \multicolumn{5}{|c|}{ Attack frequency (/year): } \\
\hline$\leqslant 9$ & 465 & 63.5 & 554 & 69.5 \\
\hline $10-49$ & 173 & 23.6 & 167 & 21.0 \\
\hline$\geqslant 50$ & 57 & 7.8 & 52 & 6.5 \\
\hline Missing & 37 & 5.1 & 24 & 3.0 \\
\hline \multicolumn{5}{|c|}{ Digits affected $(\mathrm{n})$ : } \\
\hline$\leqslant 2$ & 245 & 33.5 & 224 & 28.1 \\
\hline $3-7$ & 247 & 33.7 & 311 & 39.0 \\
\hline$\geqslant 8$ & 240 & 32.8 & 262 & 32.9 \\
\hline \multicolumn{5}{|c|}{ Phalanges affected (n): } \\
\hline$\leqslant 3$ & 183 & 25.0 & 172 & 21.6 \\
\hline $4-14$ & 339 & 46.3 & 394 & 49.4 \\
\hline$\geqslant 15$ & 210 & 28.7 & 231 & 29.0 \\
\hline \multicolumn{5}{|c|}{ Attacks ever disablingt: } \\
\hline No & 432 & 59.0 & 497 & 62.4 \\
\hline Yes & 287 & 39.2 & 291 & 36.5 \\
\hline Missing & 13 & 1.8 & 9 & 1.1 \\
\hline \multicolumn{5}{|c|}{ Consulted a doctor about symptoms: } \\
\hline No & 575 & 78.6 & 613 & 76.9 \\
\hline Yes & 138 & 18.9 & 167 & 21.0 \\
\hline Missing & 19 & 2.6 & 17 & 2.1 \\
\hline
\end{tabular}

* Of those with cold induced finger blanching.

†Attacks so bad that the subject had been forced on occasion to discontinue what he or she had been doing at the time.

with smoking and exposure to HTV after adjustment for the presence or absence of these other symptoms and also for age. In men smoking was associated with an increased risk of cold induced blanching overall (PR 1.4, 95\% CI 1.2 to 1.6 ), but not with medical consulta-

Table 4 Relation between smoking, exposure to hand transmitted vibration, and cold induced finger blanching

\begin{tabular}{|c|c|c|c|c|c|}
\hline \multirow[b]{2}{*}{ Lifetime exposure } & \multirow[b]{2}{*}{$n^{\star}$} & \multicolumn{2}{|c|}{ Any cold induced blanching } & \multicolumn{2}{|c|}{$\begin{array}{l}\text { Consulted a doctor about } \\
\text { cold induced blanching }\end{array}$} \\
\hline & & $n$ & $P R(95 \% C I)$ & $n$ & $P R(95 \% C I)$ \\
\hline \multicolumn{6}{|l|}{ Men: } \\
\hline \multicolumn{6}{|l|}{ Smoking: } \\
\hline Never & 2885 & 207 & 1.0 & 42 & 1.0 \\
\hline Ever & 3437 & 460 & $1.4(1.2,1.6)$ & 80 & $1.0(0.7,1.4)$ \\
\hline \multicolumn{6}{|c|}{ Exposure to hand transmitted vibration: } \\
\hline Never & 3314 & 220 & 1.0 & 37 & 1.0 \\
\hline Only in leisure & 306 & 31 & $1.4(1.0,2.0)$ & 6 & $1.7(0.7,3.9)$ \\
\hline Only at work & 2107 & 296 & $2.0(1.7,2.3)$ & 55 & $2.2(1.5,3.4)$ \\
\hline Work and leisure & 595 & 120 & $2.5(2.1,3.1)$ & 24 & $3.1(1.8,5.1)$ \\
\hline \multicolumn{6}{|l|}{ Women: } \\
\hline \multicolumn{6}{|l|}{ Smoking: } \\
\hline Never & 2957 & 378 & 1.0 & 68 & 1.0 \\
\hline Ever & 2413 & 336 & $1.0(0.9,1.2)$ & 70 & $1.1(0.8,1.5)$ \\
\hline \multicolumn{6}{|c|}{ Exposure to hand transmitted vibration: } \\
\hline Never & 4812 & 611 & 1.0 & 114 & 1.0 \\
\hline Only in leisure & 129 & 26 & $1.5(1.0,2.1)$ & 2 & $0.5(0.1,2.1)$ \\
\hline Only at work & 380 & 63 & $1.2(1.0,1.5)$ & 20 & $1.9(1.2,3.1)$ \\
\hline Work and leisure & 49 & 14 & $2.1(1.3,3.2)$ & 2 & $1.4(0.3,5.2)$ \\
\hline
\end{tabular}

*A few subjects did not answer all the questions.

Risk estimates were derived from a single regression model with adjustment for age, report of frequent headaches, and reports of often feeling tired or stressed. Models were fitted separately for men and women.

Table 5 Estimated proportions of cases of Raynaud's phenomenon in Britain that are attributable to hand transmitted vibration

\begin{tabular}{lll}
\hline Case definition & $\begin{array}{l}\text { Adjusted PR (95\% } \\
\text { CI) ever v never } \\
\text { exposed to HTV }\end{array}$ & $\begin{array}{l}\text { Attributable \% } \\
\text { (95\% CI) }\end{array}$ \\
\hline Men: & $2.0(1.8$ to 2.3$)$ & $31.5(25.0$ to 37.9) \\
$\quad$ Any blanching & $2.1(1.8$ to 2.4$)$ & $32.2(25.2$ to 39.3) \\
$\quad$ Cold induced blanching & $2.1(1.6$ to 2.7$)$ & $32.8(21.9$ to 43.7$)$ \\
$\quad$ Cold induced blanching with a clear edge & $2.3(1.6$ to 3.5$)$ & $37.6(21.2$ to 54.1$)$ \\
$\quad$ Consulted a doctor for cold induced blanching & $1.4(1.1$ to 1.6$)$ & $3.7(1.5$ to 5.8$)$ \\
$\quad$ Any blanching & $1.4(1.1$ to 1.6$)$ & $3.6(1.1$ to 6.1$)$ \\
$\quad$ Cold induced blanching & $1.3(0.9$ to 1.8$)$ & $3.1(-1.1$ to 7.4$)$ \\
$\quad$ Cold induced blanching with a clear edge & $1.5(1.0$ to 2.4$)$ & $5.3(-1.1$ to 11.8$)$ \\
\hline Consulted a doctor for cold induced blanching
\end{tabular}

^Bootstrapped $95 \%$ CI, based on 200 resampling iterations. tion for the symptom. No association with smoking was found in women.

Occupational and leisure time exposure to vibration were both associated with symptoms, including those leading to medical consultation. The relation was evident in both sexes, but stronger in men than women. For example, in comparison with men who had never been exposed to HTV, the PR for cold induced blanching in those exposed both at work and in leisure was 2.5 (95\% CI 2.1 to 3.1), whereas the corresponding risk estimate in women was 2.1 (95\% CI 1.3 to 3.2). Furthermore, the association between HTV and cold induced finger blanching was specific. Thus, no increased risk of the symptom was found with exposure to whole body vibration from industrial vehicles (PR in men 1.1, 95\% CI 0.7 to 1.6). Nor did exposure to HTV carry any marked increase in the risk of low back pain (PR in men $1.1,95 \%$ CI 1.0 to 1.1 ).

Tables 3 and 4 record findings in relation to cold induced finger blanching, but similar patterns were apparent for finger blanching overall and for cold induced finger blanching with a clear edge. Thus, in men who had been exposed to HTV both at work and in leisure the PR for blanching overall was 2.4 (95\% CI 2.0 to 2.9), and that for cold induced finger blanching with a clearly demarcated edge was 2.9 (95\% CI 2.0 to 4.0$)$.

Table 5 gives estimates of the proportion of cases of Raynaud's phenomenon in Britain that are attributable to exposure to HTV. In men about a third of cases are estimated to arise from exposure to HTV, and this estimate was little affected by varying the case definition. In men who consulted a doctor about cold induced blanching the attributable proportion was slightly higher (37.6\%). In men who reported extensive blanching (that is, blanching affecting at least eight of the digits or 15 phalanges), the estimated attributable number of cases nationally was 222000 . In women, by contrast, estimates of the attributable proportion were much lower: $<4 \%$ for blanching overall and 5.3\% among those who had consulted a doctor about the problem.

\section{Discussion}

Our findings indicate that Raynaud's phenomenon is common in the general population, that more than $2 \%$ of adults have consulted a doctor about the problem, and that among men who present to a doctor with the disorder more than a third are likely to have developed it through exposure to HTV.

The sample selected for study was chosen to provide information that within each occupation would be representative of Britain as a whole, and it included more than 21000 men and women from general practices across the country. In Britain almost all people register with a National Health Service general practitioner (apart from members of the armed forces, who were sampled separately). Nevertheless, bias could have arisen if subjects from certain occupations or with finger blanching responded preferentially to the questionnaire. To test for this, we compared the distri- 
bution of occupations in the responders with that at the national census and also the prevalence of symptoms in people who responded with and without a reminder (table 2). In both cases only minor differences were found.

Another potential source of error was inaccuracy in the information about disease and exposure that was obtained from the postal questionnaire. Previous community surveys which ascertained finger blanching by the same question ${ }^{15}$ or a similar question ${ }^{16}$ to that used in our study have found a predictive value of about $80 \%$ for Raynaud's phenomenon as judged by follow up medical interview; and before using our questionnaire, we tested its validity in a sample of patients from rheumatology and general practice clinics, including 18 with a clinical diagnosis of Raynaud's phenomenon. Against this standard, the questions about finger blanching were found to have a high sensitivity (94\%-100\%) and good specificity $(75 \%-78 \%) .{ }^{17}$ Some errors of recall may have arisen as the analysis was based on a lifetime rather than a recent history of finger blanching, but the disease tends to persist, and almost all of our cases indicated that blanching had occurred in the past 12 months.

We explored the accuracy with which the questionnaire ascertained exposures to HTV in subjects' current jobs, and found that reports were generally plausible. ${ }^{18}$ None the less, associations between HTV and blanching could have been exaggerated if symptomatic subjects tended to recall exposure better than the average, or if people exposed to vibration were more aware of symptoms than those who were not exposed. That finger blanching was reported more often by subjects who also complained of frequent headaches or tiredness and stress suggests that people do vary in their propensity to report symptoms. However, the association of HTV with blanching persisted after adjustment for these other complaints, whereas no such association was found with back pain. Moreover, the risk of finger blanching was not increased in subjects exposed to whole body vibration from industrial vehicles. This specificity of the relation between HTV and finger blanching argues against major inflation of risk estimates from reporting bias. Also, if risks were spuriously increased from biased ascertainment of symptoms, associations might be expected to be stronger for finger blanching overall than for the more specific complaint of cold induced blanching with a clear edge; but this was not found.

Two previous surveys have examined the prevalence of Raynaud's phenomenon in British communities. Among 450 adults aged 20-59 years who were registered with a Hampshire general practice, the prevalence of episodic finger blanching was $8.3 \%$ in men and $17.6 \%$ in women, ${ }^{15}$ based on a question identical to that used in this study. And a survey of patients from five general practices in London, Merseyside, and Cheshire found that the prevalence of cold induced blanching associated with numbness and parasthesiae was $11 \%-16 \%$ in men and $19 \%-21 \%$ in women. ${ }^{19}$ Our findings, based on a much larger and geo- graphically more representative sample, are broadly similar, with again a higher prevalence in women than in men. Studies in other countries have suggested that Raynaud's phenomenon is more common in colder climates. ${ }^{2021}$ We found little variation in the prevalence by region or by season, but age adjusted rates were markedly lower in military personnel than civilians. This may reflect a different attitude in the services to the reporting of what may be perceived as minor symptoms, and it is possible that a healthy worker selection effect has also contributed.

Around one fifth of cases in our study had consulted a doctor about their symptoms. Thus, it is important for physicians to be aware of risk factors for the disorder, particularly where they might offer scope for secondary prevention. Smoking has been reported to cause acute digital vasoconstriction, ${ }^{22}$ and has been associated with Raynaud's phenomenon in a few previous studies. ${ }^{2324} 25$ We found an increased risk of finger blanching in male smokers, but the PR was only 1.4, and there was no corresponding association in women. Our analysis was aimed at determining whether smoking predisposes to the development of Raynaud's phenomenon, and for this purpose we used lifetime histories of smoking and finger blanching. We cannot exclude the possibility that smoking acutely exacerbates pre-existing disease, but our findings suggest that any impact it has on the incidence of new disease is small.

By comparison, the influence of exposure to HTV is much greater, especially in men among whom it carried a doubling of risk and accounted for about a third of all cases. The impact of HTV at a national level has not been systematically investigated previously. Estimates of the frequency of disease associated with vibration have come largely from compensation claims under the Department of Social Security's Industrial Injuries Scheme and from employers' statutory reports under the Reporting of Injuries, Diseases and Dangerous Occurrences (RIDDOR) Regulations, ${ }^{26}$ but these official schemes, which are heavily influenced by awareness and willingness to report, do not provide an adequate basis for determining the number of attributable cases. Information is also available from two labour force surveys carried out by The Health and Safety Executive in 1990 and $1995 .{ }^{27}{ }^{28}$ These suggest a lower attributable proportion-no more than $5 \%$ in men assuming a prevalence of $5 \%$ for Raynaud's phenomenon in the general population. However, in these surveys no direct inquiry was made about finger blanching (only work related illnesses in general). Moreover, cases were only ascertained if they themselves attributed their disease to an occupational exposure, and the link with occupation often may not be apparent to the person concerned.

Elsewhere, a study in South Carolina found crude odds ratios of 1.9-2.0 in men and 1.4 in women for the association of HTV exposure with cold sensitivity and colour changes in the fingers or toes ${ }^{29}$; and a multicentre investigation in France and the United States found an odds 
ratio of 1.93 for Raynaud's phenomenon in people who had used vibratory tools. ${ }^{20}$ These risk estimates are compatible with ours.

The fact that many of our cases had consulted a doctor about their finger blanching underlines the need for general practitioners to be aware of the relation between Raynaud's phenomenon and HTV. Treatment options for established cases are limited, but there is some evidence that symptoms may improve (over several years) in workers who withdraw from or limit further exposure to HTV. ${ }^{30-33}$ In one study, a diminished prevalence of symptoms in former chain saw users was accompanied by an improvement in measured finger blood flow, but there was less improvement in older subjects and those with more advanced disease, suggesting that early withdrawal may be particularly beneficial. Continued exposure, by contrast, may cause symptoms to worsen. ${ }^{24}{ }^{34-39}$ It follows that the scope for avoiding or reducing exposure is worth exploring. How far this is pursued, however, will depend on the severity of disease and the potential cost to the patient-for example, in reduced incomefrom a change in the work he does. It is also possible that the patient will be eligible for compensation if their illness has been caused by work.

Our findings are also important in emphasising the public health impact of HTV. They suggest that the numbers in Britain who may benefit from screening, counselling, and compensation are larger than previously supposed, and that a higher priority should be accorded to controlling the risks from this common occupational hazard.

We are grateful to the Royal College of General Practitioners, the Primary Care Rheumatology Society, HM Armed Forces, the 34 general practices that assisted in assembling the lists for questionnaires, and the MRC staff who were involved in data handling. We are particularly indebted to Ian Bowes and Vanessa Cox for their role in the collection and processing of the data. Denise Gould prepared this manuscript.

1 Raynaud M. On local asphyxia and symmetrical gangrene of the extremities 1862, and new research on the nature and treatment of local asphyxia of the extremities (1872 trans). In: Barlow T. Selected monographs (121). London: New Sydenham Society, 1888.

2 Coffman JD. Raynaud's phenomenon. Oxford: Oxford University Press, 1989.

3 Lorigia G. Il Lavorco co i martelli pneumatici? Bolletino Inspettione Lavoro 1911;2:35-60.

4 Hamilton A. A study of spastic anaemia in the hands of stonecutters. Washington, DC: United States Bureau of Labor cutters. Washington, DC: United States Burea
Statistics, 1918:53-66. (Bulletin 236, part 19.)

Statistics, 1918:53-66. (Bulletin 236, part 19.)
5 Hunter D, McLaughlin AIG, Perry KMA. Clinical effects of the use of pneumatic tools. Br F Ind Med 1945;2:10-16.

6 Grounds MD. Raynaud's phenomenon in users of chain saws. Med $\mathcal{F}$ A A ust 1964;1:270-2.

7 Taylor W, Pearson J, Kell RL, et al. Vibration syndrome in Forestry Commission chain saw operators. $\mathrm{Br} F$ Ind $\mathrm{Med}$ 1971;28:83-9.

8 Taylor W, Pelmear PL. Vibration white finger in industry. London: Academic Press, 1975.

9 Pyykko I, Korhonen O, Farkkila M, et al. A longitudinal study of vibration syndrome among Finnish forest workers. In: Brammer AJ, Taylor W, eds. Vibration effects on the hand and arm in industry. New York: John Wiley, 1982:157-67.

10 Palmer KT, Griffin MJ, Bendall $\mathrm{H}$, et al. The prevalence and pattern of occupational exposure to hand-transmitted vibration in Great Britain: findings from a national survey. Occup Environ Med 2000;57:218-28.

11 Palmer K, Coggon D, Pannett B, et al. The development of a self-administered questionnaire to assess exposures to hand-transmitted and whole-body vibration and their health effects. F Sound Vib 1998;215:653-86.

12 Zocchetti C, Consonni D, Bertazzi PA. Estimation of prevalence ratios from cross-sectional data. Int f Epidemiol 1995; 24:1064-5.

13 Office of Population Censuses and Surveys. Census 1991: conomic activity report. London: The Stationery Office, 1993

14 Efron B, Tibshirani R. An introduction to the bootstrap. New York: Chapman and Hall, 1993.

15 Heslop J, Coggon D, Acheson ED. The prevalence of intermittent digital ischaemia (Raynaud's phenomenon) in a general practice. Fournal of the Royal College of General Practictioners 1983;33:85-9.

16 Leppert J, Aberg H, Ringqvist I, et al. Raynaud's phenomenon in a female population: prevalence and
association with other conditions. Angiology 1987;38:8717 .

17 Palmer K, Smith G, Kellingray S, et al. Repeatability and validity of an upper limb and neck discomfort questionnaire: the utility of the standardised Nordic questionnaire. Occup Med 1999;49:171-5.

18 Palmer KT, Haward BM, Griffin MJ, et al. The validity of self reported occupational exposures to hand transmitted and whole body vibration. Occup Environ Med 2000;57: $237-41$

19 Silman A, Holligans S, Brennan P, et al. Prevalence of Raynaud's phenomenon in general practice. BMF 1990;301: 590-2.

20 Maricq HR, Carpentier PH, Weinrich MC, et al. Geographic variation in the prevalence of Raynaud's graphic variation in the prevalence of Raynaud's prance. F Rheumatol 1993;20:70-6.

21 Maricq HR, Carpentier PH, Weinrich MC, et al. Geographic variation in the prevalence of Raynaud's phenomenon: a five region comparison. F Rheumatol 1997; 24:879-89.

22 Goodfield MJD, Hume A, Rowell NR. The acute effects of cigarette smoking on cutaneous blood flow in smoking and non-smoking subjects with and without Raynaud's phenomenon. Br F Rheumatol 1990;29:89-91.

23 Valter I, Maricq HR. Prevalence of Raynaud phenomenon in Tartu and Tartumaa, Southern Estonia. Scand $\mathcal{F}$ Rheumatol 1997;26:117-24.

24 Letz R, Cherniack MG, Gerr F, et al. A cross sectional epidemiological survey of shipyard workers exposed to handarm vibration. Br f Ind Med 1992;49:53-62.

25 Ekevall L, Lindbald LE. Effects of tobacco use on vibration white finger. $\mathcal{F}$ Occup Med 1989;31:13-16.

26 Health and Safety Commission. Health and safety statistics 1996-7. London: The Stationery Office, 1997.

27 Hodgson JT, Jones JR, Elliott RC, et al. Self-reported work-related illness. Sudbury, Suffolk: HSE Books, 1993. (Research paper 33.)

28 Jones JR, Hodgson JT, Clegg TA, et al. Self-reported work-related illness in 1995. Results from a household survey. London: The Stationery Office, 1998.

29 Maricq HR, Weinrich MC, Keil JE, et al. Prevalence of Raynaud phenomenon in the general population: a preliminary study by questionnaire. 7 Chronic Dis 1986;39:423-7.

30 Stewart AM, Goda DF. Vibration syndrome. Br f Ind Med 1970;27:19-27.

31 Riddle HFV, Taylor W. Vibration-induced white finger among chain sawyers 9 years after the introduction of antivibration measures. In: Brammer AJ, Taylor W, eds. Vibration effects on the hand and arm in industry. New York: John Wiley, 1982:169-72.

32 Hursh HJ. Vibration-induced white finger-reversible or not? A preliminary report. In: Brammer AJ, Taylor W, eds. Vibration effects on the hand and arm in industry. New York: John Wiley, 1982:156-67.

33 Ekenvall L, Carlsson A. Vibration white finger: a follow up study. Br F Ind Med 1987;44:476-8.

34 Miyashita K, Shiomi S, Itch N, et al. Epidemiological study of vibration syndrome in response to total hand-tool operating time. Br F Ind Med 1983;40:92-8.

35 Matsumoto K, Itoh N, Kasamatsu T, et al. A study on subjective symptoms based on total operating time of chain saw. Fpn f Ind Health 1977;19:22-8.

36 Tominaga Y. Dose-response relation for the vibration syndrome. In: Brammer AJ, Taylor W, eds. Vibration effects on the hand and arm in industry. New York: Wiley, 1982.

37 Bovenzi M. Vibration white finger among stonedrillers or cutters in the travertine industry. In: Proceedings of foint French-British meeting. Groupe Francais des Etudes des Effets des Vibrations sur l'Homme and UK Informal Group on Human Response to Vibration. Vandoeuvre, France: INRS, 26-28 September 1988.

38 Bovenzi M, Cerri S, Merseburger A, et al. Hand-arm vibration syndrome and dose-response relation for vibration induced white finger among quarry drillers and stonecarvers. Occup Environ Med 1994;51:603-11.

39 Bovenzi M, Franzinelli R, Mancini R, et al. Dose-response relation for vascular disorders induced by vibration in the fingers of forestry workers. Occup Environ Med 1995;52: $722-30$. 